\title{
DEVELOPMENT OF A RAISED RAIL-ROAD CROSSING
}

\section{Z. ZHANG, S. AGHDAMY*, M. DHANASEKAR and D.P. THAMBIRATNAM}

School of Civil Engineering and Built Environment, Queensland University of Technology, QLD 4000, Australia

Emails: zheshuo.zhang@hdr.qut.edu.au,s.aghdamy@qut.edu.au,m.dhanasekar@qut.edu.au d.thambiratnam@qut.edu.au

*Corresponding author

\begin{abstract}
When a road and rail intersect, a level crossing $(L C)$ is a cheaper alternative to over or under pass infrastructure. Australia currently has approximately 20,000 LCs; annually 37 deaths on average occur mainly as a result of the road vehicles failing to obey warning signals. In this research, it is hypothesised that the current design of $L C$ does not deter the road vehicle drivers from accelerating through the crossing, whilst a raised crossing consisting of ramps and recesses to house the rails would. This hypothesis is proved as valid through a multi-body dynamic simulation modelling method applied to a road vehicle passing through a raised crossing at various speeds. The efficacy of the raised crossing is demonstrated through numerical examples that show increase in the speed of the road vehicle reduces the vertical acceleration of the driver cabin in a $L C$ whilst the same increases the raised crossing. Where the road vehicles fail to stop and subsequently impact a running train laterally or being impacted by a train longitudinally, the derailed wheelsets impact the sides of the recesses in the raised crossing and thereby mitigating the adverse effects of the crash. This paper summarises the train-vehicle collision induced derailment process and presents the maximum impact force time series obtained from various simulations. Finally, structural design options for the raised crossing to resist the impact forces have been explored using an explicit finite element modelling.
\end{abstract}

Keywords: impact loading; raised road-rail crossing; multi-body dynamic modelling; explicit finite element modelling; failure mechanisms; parametric sensitivity analysis

\section{INTRODUCTION}

Rail-road crossing collisions involving trains and heavy road vehicles are severe safety hazards. These incidents occur more often worldwide as seen from the data provided in (Federal Railroad Administration 2016). Although the collision incidents have reduced by a third from 2001-2009, fatalities and injuries remain almost unchanged, which shows the incidents are increasingly becoming more severe. In Australia, about 100 collisions between the trains and the road vehicles at road-rail crossings occur each year, these collisions are estimated to cost $\$ 32$ million and result in the death of 37 people annually on average (Australian Transport Council 2010). Further, each year more than 300 people across Europe die in more than 1200 accidents, which account for onethird of all rail fatalities (European Commission Road safety 2010). Authorities attempt to mitigate these accidents through installation of extensive warning systems, road signs and boom gates. Unfortunately, data show that the benefit of these warning systems is insignificant to the number and severity of the incidents occurring at LCs; therefore, we have redesigned the level crossing as a system that would passively force the road vehicle drivers to reduce speed in contrast to their ability to accelerate through the current LC design, which increases the severity of collisions. 
Passive civil infrastructure solutions, for example speed humps, are shown to be effective in implicitly forcing the road vehicle drivers to reduce speed. We develop such a solution and call it as Level Crossing Accident Mitigator (LCAM) (Ling et al. 2016a, Ling et al. 2016b, Ling et al. 2016c, Ling et al. 2017a, Ling et al. 2017b, Ling et al. 2017c, Ling et al. 2017d, Zhang et al. 2018). In the conceptual design of the passive road-rail crossing structure (Fig. 1b), the level of the road is provided with two ramps and the rails are housed in deeper recesses than the LC design (Fig. 1A). The benefits envisaged of the raised crossings (RC) are: (1) railheads are not impacted by the tires of the passing road vehicles; (2) raised recesses act as guard rails to reposition the derailed wheelsets of trains (impacted by road vehicles failing to stop or the trains longitudinally impacting road vehicles) back onto the rails and (3) the RC acts similar to road humps that passively force the road vehicle drivers to reduce speed and not accelerate as they do in most cases of severe LC accidents.

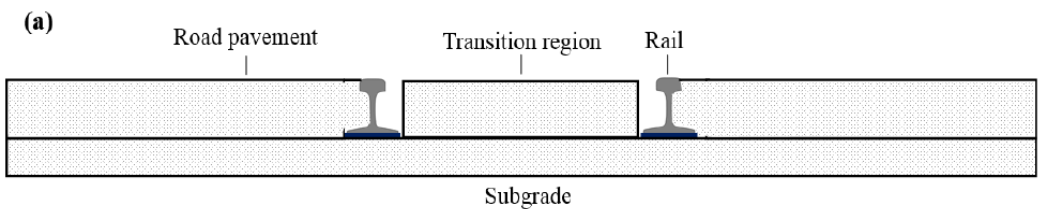

(b)

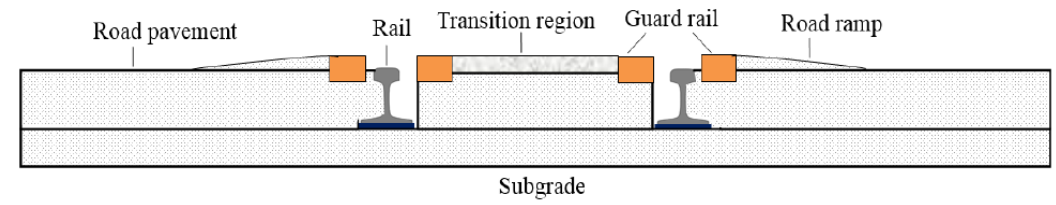

Figure 1 Track structures at road-rail crossing: (a) current design; (b) proposed design

LC infrastructure is managed by the rail authorities, although road and civic authorities are significant stake holders (Dhanasekar and Bayissa 2012). Therefore, the management system of the proposed RC would also remain the same. As the road vehicles do not impart loading on the rails in deep recesses in the $\mathrm{RC}$, rail authorities expect lower maintenance of the rail and the track structure near the RC infrastructure; however, road authorities should approve the RC before it can be implemented. With a view to providing data for the informed decision making of the road authorities, several simulations of the road vehicle - RC structure interaction have been carried out and key results are presented first. The results show that the RC has high potential to force the road vehicles to reduce their operating speed whilst crossing the rail track; however, the potential for road vehicles even though under severe braking to laterally impact passing trains cannot be ruled out. Such events could lead to dislodgement of wheelsets of the running trains. Dislodged wheelsets impacting the sides of the recesses of the RC generating impact forces has, therefore, been modelled and the impact force spectra are presented in this paper. Finally, two options of the RC have been modelled using explicit finite element method to ensure structural safety under lateral impact.

\section{MODELLING OF A ROAD VEHICLE CROSSING THE RC}

Multi-body dynamic (MBD) modelling method was used for the simulation of road vehicles crossing RC; a nine DOF 2D vehicle model comprising of a driver cabin, trailer and five tires as shown in Fig. 2 was used. The model consisted of seven vertical degrees of freedom (DOF) corresponding to five vertical motions, viz, one driver cabin $z_{u}$, one trailer $z_{a}$ and five wheels $z_{t i, i=1,5}$ and two pitch DOFs $\theta_{u}$ and $\theta_{a}$ representing the cabin and trailer respectively. Symbols $M_{u}, M_{a}$, and $M_{i, i=1,5}$ represent the masses of the cabin, trailer and five axles, respectively. Symbols $I_{u}$ and $I_{a}$ represent the moments of inertia of the cabin and the trailer in the pitch direction, respectively. A fifth wheel joint (Fig. 2) was assumed to represent the articulation between the cabin and the trailer using a pair of spring and damper of stiffness $k_{j}$ and damping coefficient $c_{j}$. The 
flexible tires were modelled using enveloping tire model (ETM) normally used for characterising accelerations of road vehicles travelling along rough roads. ETM is a simplified model that allows for the flexibility of tire - road contact surface (through experimental constants for contact length parameters), whilst determining the road surface characteristics from an idelaised coupled rigid elliptic cam inscribed within the flexible tire. ETM was re-formulated for application to the RC.

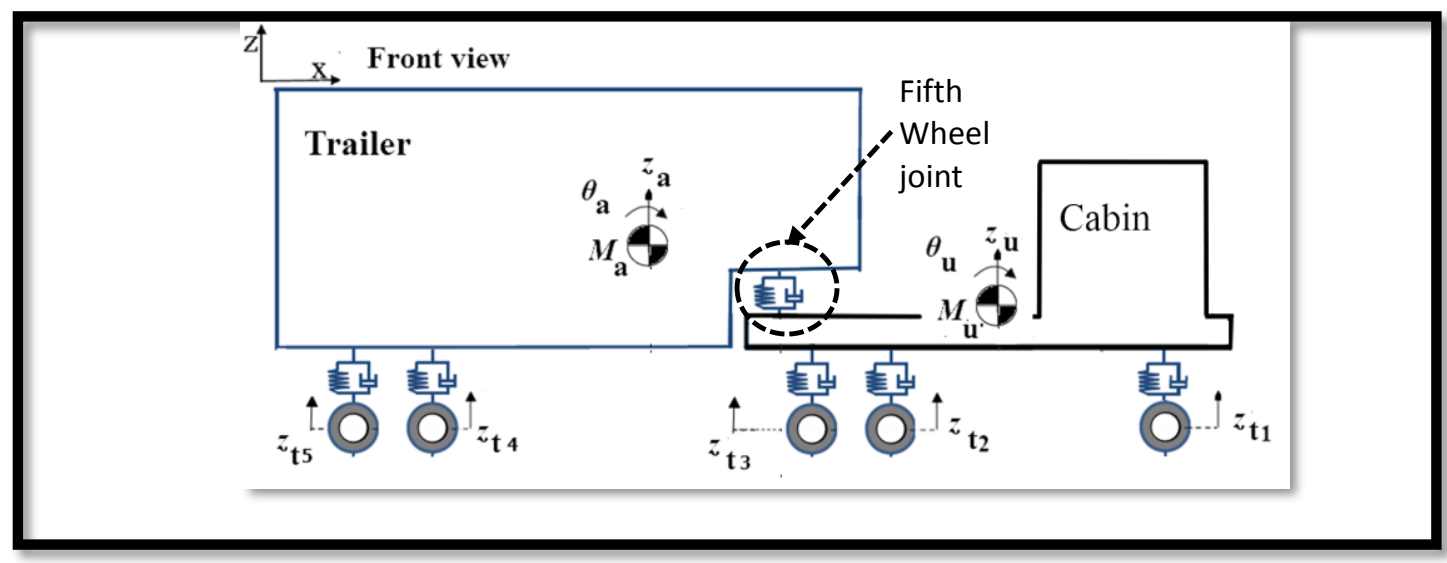

Figure 2 Multi-Body Dynamic Model of an articulated heavy road vehicle.

At each time step, the displacement and velocity of tire and vehicle body were determined using nil acceleration as initial condition in an explicit integration method. The tire properties were checked, and the effective RC structure profile was calculated. Based on this information, the tire model calculated the tire forces, which were transferred to the rims for determining the sprung cabin and trailer vibration signatures. This process was repeated until convergence of each time step for the whole of the travel time. The results from the simulation (one for crossing RC and the other for crossing LC) are presented in Fig. 3(a) and Fig. 3(b) respectively.

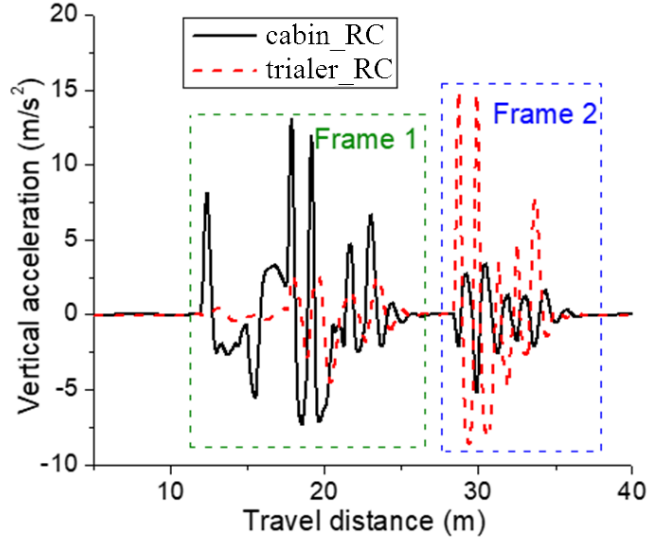

(a) Vehicle passing RC

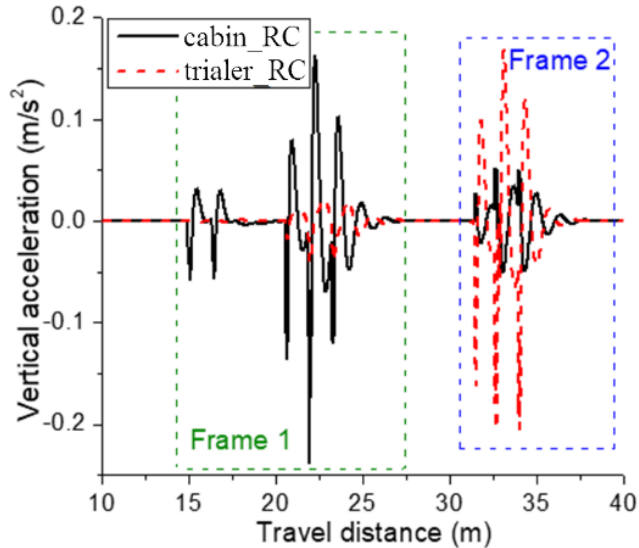

(b) Vehicle passing LC

Figure 3 Vertical accelerations of sprung bodies of the vehicle passing RC and LC.

Fig. 3(a) shows the accelerations of the sprung bodies passing the RC; in frame 1, cabin has high vibration while trailer vibration is relatively weak; in frame 2, the trend reverses. Fig. 3(b) illustrates the accelerations of the sprung bodies passing the normal LC which generates much smaller vibration signatures to the vehicle accelerations compared with the RC. The peak acceleration (PA) of the sprung bodies crossing the RC is $\sim 15 \mathrm{~m} / \mathrm{s} 2(1.5 \mathrm{~g})$ while the same bodies crossing LC exhibit negligible vertical acceleration $(\sim 0.18 \mathrm{~m} / \mathrm{s} 2)$.

Several simulations of the heavy vehicle passing the RC and the LC were carried out; travelling speeds were varied from $10 \mathrm{~km} / \mathrm{h}$ to $70 \mathrm{~km} / \mathrm{h}$; braking (Handoko and Dhanasekar 2006) was not considered - all simulations were carried out under constant travel speed. The peak acceleration 
(PA) of the driver cabin were chosen from the signatures and plotted in Fig. 4. Fig. 4 shows that the PA for cabin decreases with increasing speed while it crosses the LC - whereas it increases whilst crossing the RC. This means that driving at higher speed through the LC would be more comfortable for the driver - which partly explains the reason for speeding through LCs. As the redesigned RC would cause significant vertical acceleration under higher speeds, it can potentially mitigate this behaviour based on the results shown in Fig. 4(a). Approximately $40 \mathrm{~km} / \mathrm{h}$ speed is shown to limit the vertical acceleration to approximately $12 \mathrm{~m} / \mathrm{s}^{2}$. As rail crossings are not encountered too frequently on roads, a one-off vertical acceleration of $12 \mathrm{~m} / \mathrm{s}^{2}$ (a little over $1 \mathrm{~g}$ ) would not cause harm. Trailer response also exhibited similar trend - for brevity, it is not shown here.

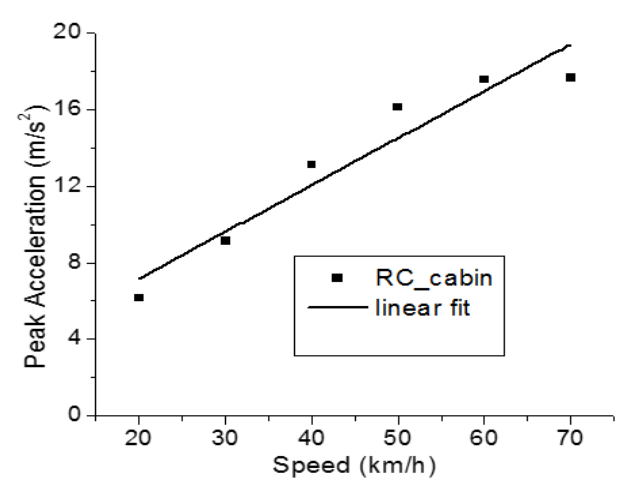

(a) $P A$-RC

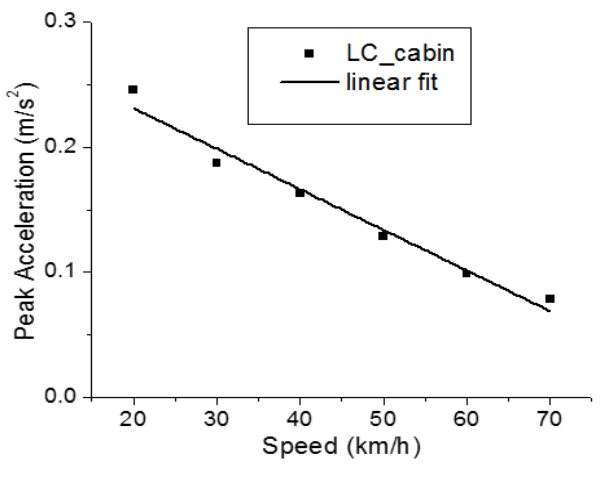

(b) $P A$-LC

Figure 4 The $P A$ for cabin and trailer passing RC and LC under various speeds.

\section{STRUCTURAL DESIGN OPTIONS FOR THE RAISED CROSSING}

Different design options for RC were considered and efficacy of each was investigated using numerical simulations. In this paper, two of the considered design options are presented and discussed. The first option considered the RC to be made of concrete and the second option considered the RC made of concrete and protected at its edge with steel plates (Fig. 5). The numerical model of a RC structure subjected to impact loading was developed employing the verified numerical techniques for the simulation of steel-concrete composite members subjected to lateral impact loading in comparison with experimental results presented in Aghdamy et al. (2016). The explicit dynamic nonlinear finite element code LS-DYNA (LS-DYNA-Livermore Software Technology Corp 2015) was used to establish the finite element analysis (FEA) models. LS-PrePost software was then used as the post-processor to process the results from LS-DYNA analyses.

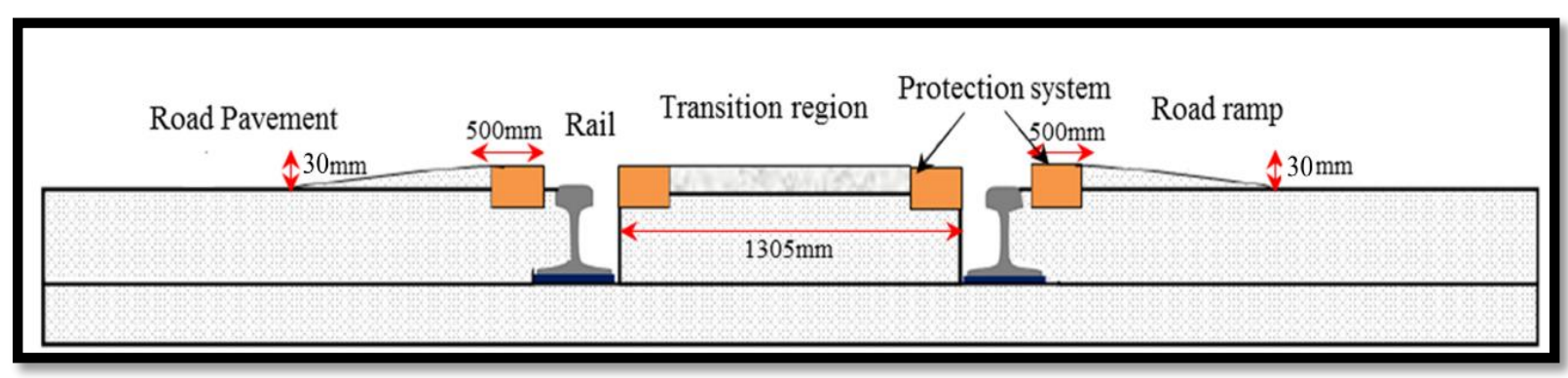

Figure 5 Optimal Dimensions of RC

The geometry of the RC (Fig. 5) was determined from both the constraints imposed by the clearance between the underside of the passenger car/ locomotive/ freight or coal wagons as well 
as the vertical acceleration of the cabin and trailer of the road vehicles from the simulation described in Section 2 of this paper. The slope angle was set as $4^{\circ}$, the maximum height above the road surface level was $30 \mathrm{~mm}$, width of the gap was $160 \mathrm{~mm}$ and the distance between the edges of recesses was $1305 \mathrm{~mm}$. Risk to repetitive loading on edges and corners were also minimised using the principles in (Ding and Dhanasekar 2007, Jia and Dhanasekar 2007, Bandula-Heva et al. 2013).

\subsection{Simulation of Impact Loading on RC}

The RC was subject to loading from the road vehicles in the vertical direction and impact due to derailed wheelsets in the lateral direction; the lateral impact load was found to be more severe than the vertical loading and hence was used for the design of the RC (Ling et al. 2016, Ling et al. 2016, Ling et al. 2016, Ling et al. 2017, Ling et al. 2017, Ling et al. 2017, Ling et al. 2017, Zhang et al. 2018). It was found that the impact loading caused by the derailed wheelsets of trains longitudinally impacting the stranded road vehicle was the largest (shown in Fig. 6). This load was associated with a frontal collision of a train running at an average operational speed of $125 \mathrm{~km} / \mathrm{hr}$ onto a 40 Tonne stranded cabin (average mass of a heavy vehicle) at an angle of 15 degrees. The load was converted to average contact pressure using the projected web area of the wheels onto the sides of the recess as shown in the insert in Fig. 6.

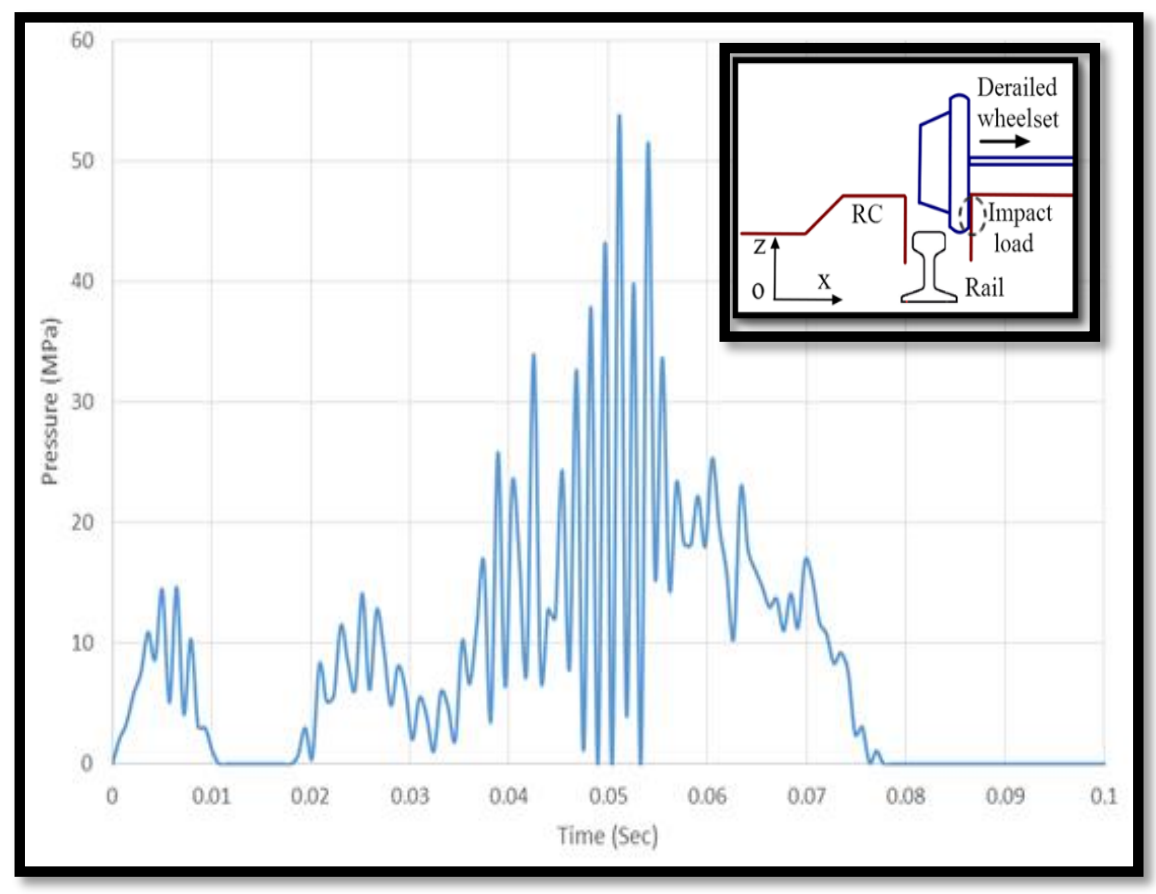

Figure 6 Impact pressure-time history

\subsection{FE Model of a RC Structure Subjected to Impact Loading}

The transition region of the RC structure with the length of $1305 \mathrm{~mm}$, width of 3600 (typical onelane road width) and thickness of $220 \mathrm{~mm}$ was modeled in this study. The steel protection system was assumed to be $3 \mathrm{~mm}$ thick and to have the flange width and web depth of $220 \mathrm{~mm}$. Subgrade was not modelled. Concrete was modelled using 8-node hexahedron "constant stress" solid elements with one-point Gauss integration. The steel protection system used in the option-2 was modelled using Belytschko-Tsay 4-node quadrilateral thin shell elements with five integration points through the thickness. A mesh convergence study was performed to find a mesh size, which satisfactorily balances accuracy and computing resources. Figs. 7(a) and 7(b) show the FE models for the concrete and the steel cladded RC structure respectively. 
MAT_CONCRETE_DAMAGE_REL3 incorporating DIF-strain rate effects using the relationship recommended by (CEB-FIP 1993) and (Malvar and Crawford 1998) was employed to simulate the behaviour of concrete under impact loading. The concrete was assumed to have a compressive strength, density and maximum aggregate size of $32 \mathrm{MPa}, 2400 \mathrm{~kg} / \mathrm{m}^{3}$ and $20 \mathrm{~mm}$, respectively. MAT_PIECEWISE_LINEAR_PLASTICITY incorporating strain rate effects using Cowper-Symonds coefficients $(\mathrm{C}=40.4$ and $\mathrm{p}=5)$ were employed to model steel, which was assumed to have a yield strength of 270MPa. To model the strain-hardening branch of stress- strain curve, the relationship proposed by (Gattesco 1999) was used. Since the adhesive connecting mechanism was considered to connect the steel to concrete in the second option, CONTACT_AUTOMATIC_SURFACE_SURFACE_TIEBREAK algorithm with the static friction coefficient of 0.57 and dynamic friction coefficient of 0.45 was employed to model the interaction. The adhesive to connect concrete and steel was assumed to be Sikadur ${ }^{\circledR} 30$, which is a structural epoxy paste suitable for structural bonding between concrete and steel. This adhesive has the compressive strength of $85 \mathrm{MPa}$, tensile strength of $30 \mathrm{MPa}$ and bond strength of $33 \mathrm{MPa}$ and $4 \mathrm{MPa}$ with steel and concrete, respectively. Additionally, the train wheel was modelled using 8 node hexahedron "constant stress" solid elements with one-point Gauss integration considering the wheel profile for the Australian passenger train vehicle (ANZR1; diameter: 920mm; rim thickness $=25 \mathrm{~mm}$ ). The uncoupled load analysis method was performed in this investigation. Therefore, the modelling of the train wheel was only done to find a realistic location of the applied impact load. The wheel was removed from the FEA model after finding the elements of the surface which would be in contract with the wheel during the impact. The impact load (Fig. 6) was then applied as a surface pressure on those elements of the surface. This impact load which is caused by derailed wheelsets impacting the RC was obtained from (Ling et al. 2017c). Fixed boundary condition was applied at the bottom of this structure.

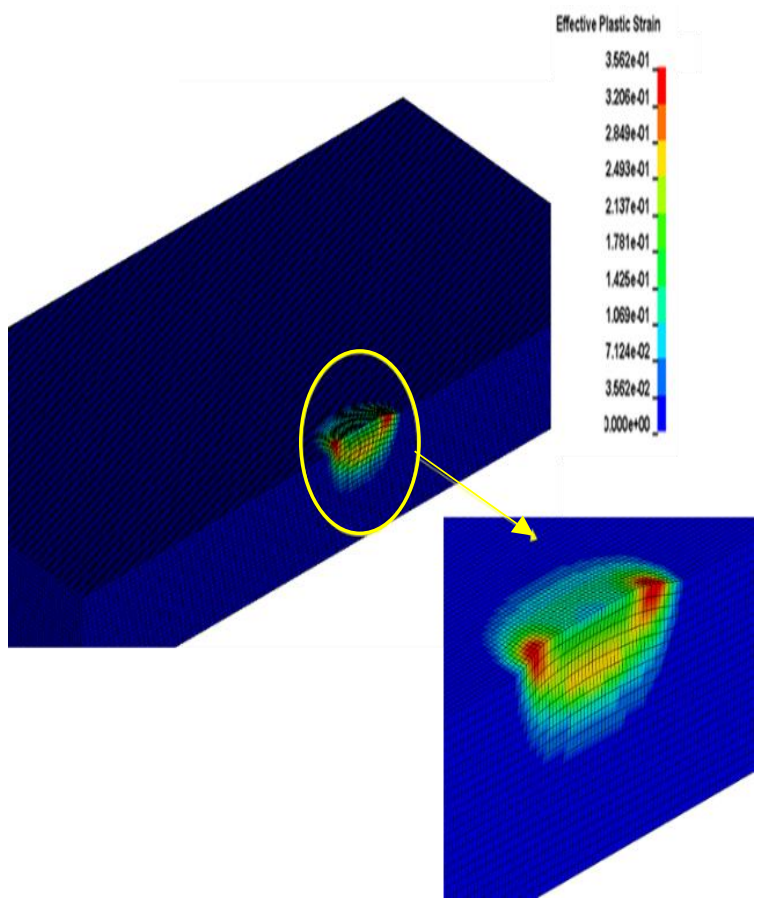

(a) Concrete RC Structure

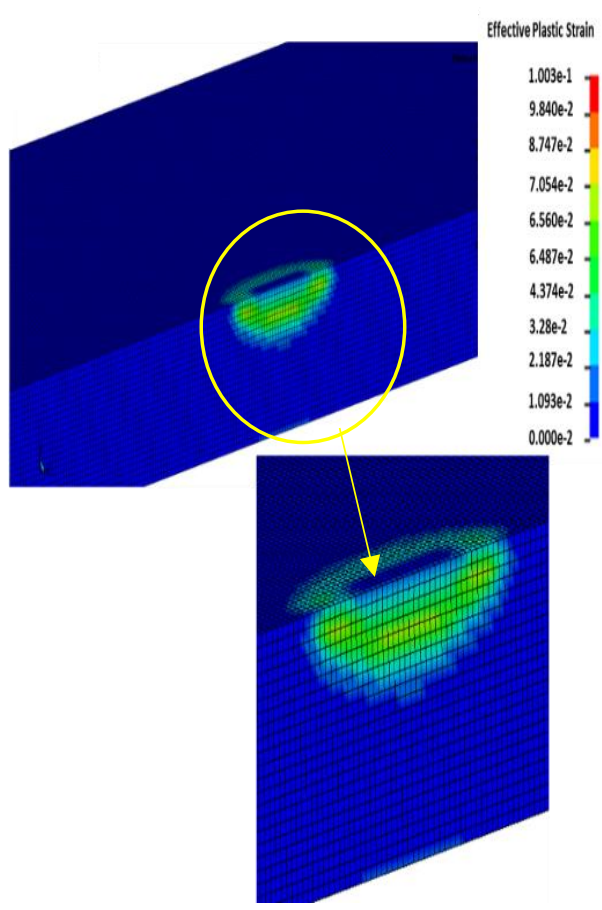

(b) Steel Plate Protected RC Structure

Figure 7 Contours of effective plastic strain for two options of the RC Structural Systems 


\subsection{COMPARISON BETWEEN DESIGN OPTIONS}

Figs $7 \mathrm{a}$ and $7 \mathrm{~b}$ show the contours of effective plastic strain in the $\mathrm{RC}$ concrete structure and $\mathrm{RC}$ concrete structure with $3 \mathrm{~mm}$ steel edge protected system respectively, after the impact. It is clear from Fig $7 \mathrm{~b}$ that use of a $3 \mathrm{~mm}$ steel edge protected system has significantly improved the behaviour through reduction in stress concentration. Additionally, Figure 8 shows the local deflection-time history for the two options, where the thickness of the steel in the second option is only $3 \mathrm{~mm}$. As it can be seen from this figure, providing the $3 \mathrm{~mm}$ steel edge protection system has significantly diminished the local deformation at the impact location due to reduction in stress concentration.

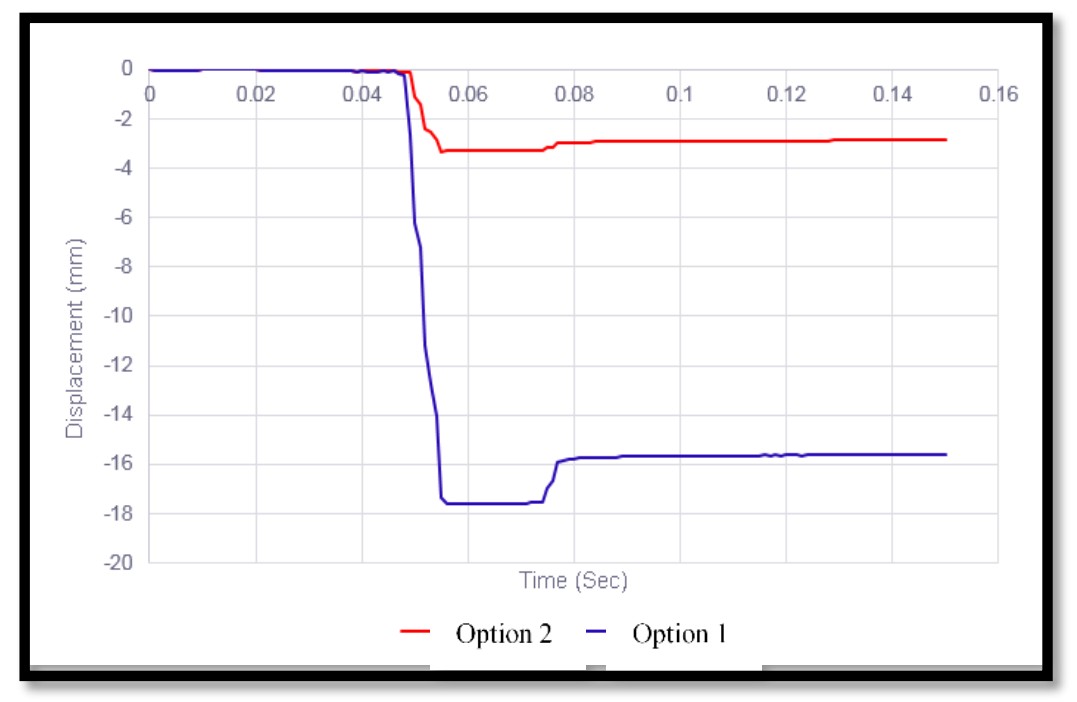

Figure 8 Local displacement-time history for the RC concrete structure (option 1) and steel plate protected RC concrete structure (option 2)

\section{CONCLUSION}

This paper presented the results of an investigation carried out to develop an innovative raised rail crossing consisting of ramps and recesses to house the rails. Multi-body dynamic simulation modelling method was formulated and used to conduct several simulations of the road vehicle $-\mathrm{RC}$ structure interaction at various speeds. The efficacy of the raised crossing was then compared to the level crossing. The results show that the $\mathrm{RC}$ has high potential to force the road vehicles to reduce their operating speed whilst crossing the rail track; however, potential for road vehicles under severe braking laterally impacting passing trains cannot be ruled out. Such events could lead to dislodgement of wheelsets of the running trains. Dislodged wheelsets impacting the sides of the recesses of the RC generating impact loads have therefore been modelled and the impact force spectra described in this paper. Finally, the developed numerical model of RC structure subjected to lateral impact loading was employed to investigate the efficacy of two design options, namely concrete RC structure and concrete RC structure with steel edge protection system. The results of the study show that the use of a steel edge protected system can significantly reduce the stress concentration at the impact location which results in substantial reduction in local deformation.

\section{REFERENCES}

Aghdamy, S., D. P. Thambiratnam, M. Dhanasekar and S. Saiedi (2016). "Effects of structurerelated parameters on the response of concrete-filled double-skin steel tube columns to lateral impact." Thin-Walled Structures 108: 351-368. 
Australian Transport Council (2010). National Railway Level Crossing Safety StrategyAustralia-2010-2020.

Bandula-Heva, T., M. Dhanasekar and P. Boyd (2013). "Experimental investigation of wheel/rail rolling contact at railhead edge." Experimental Mechanics 53(6): 943-957.

CEB-FIP (1993). Design Code, Comité Euro-International duBéton, Thomas Telford Services Ltd, London.

Dhanasekar, M. and W. Bayissa (2012). "Performance of square and inclined insulated rail joints based on field strain measurements." Proceedings of the Institution of Mechanical Engineers, Part F: Journal of Rail and Rapid Transit 226(2): 140-154.

Ding, K. and M. Dhanasekar (2007). "Flexural behaviour of bonded-bolted butt joints due to bolt looseness." Advances in Engineering Software 38(8-9): 598-606.

European Commission Road safety (2010). International level crossing awareness day (ILCAD). Brussels: European Commission; .

Federal Railroad Administration (2016). Highway-rail crossing collisions \& casualties by year. Office of Safety Analysis, Federal Railroad Administration, USA.

Gattesco, N. (1999). "Analytical modeling of nonlinear behavior of composite beams with deformable connection." Journal of Constructional Steel Research 52(2): 195-218.

Handoko, Y. and M. Dhanasekar (2006). "An inertial reference frame method for the simulation of the effect of longitudinal force to the dynamics of railway wheelsets." Nonlinear dynamics 45(3-4): 399-425.

Jia, S. and M. Dhanasekar (2007). "Detection of rail wheel flats using wavelet approaches." Structural Health Monitoring 6(2): 121-131.

Ling, L., M. Dhanasekar and D. P. Thambiratnam (2017a). "Assessment of road-rail crossing collision derailments on curved tracks." Australian journal of structural engineering 18(2): $125-134$.

Ling, L., M. Dhanasekar and D. P. Thambiratnam (2017b). "Dynamic response of the traintrack-bridge system subjected to derailment impacts." Vehicle System Dynamics: 1-20.

Ling, L., M. Dhanasekar and D. P. Thambiratnam (2017c). "Frontal collision of trains onto obliquely stuck road trucks at level crossings: Derailment mechanisms and simulation." International Journal of Impact Engineering 100: 154-165.

Ling, L., M. Dhanasekar and D. P. Thambiratnam (2017d). "A passive road-rail crossing design to minimise wheel-rail contact failure risk under frontal collision of trains onto stuck trucks." Engineering Failure Analysis 80: 403-415.

Ling, L., M. Dhanasekar, D. P. Thambiratnam and Y. Q. Sun (2016a). "Lateral impact derailment mechanisms, simulation and analysis." International Journal of Impact Engineering 94: 36-49.

Ling, L., M. Dhanasekar, D. P. Thambiratnam and Y. Q. Sun (2016b). "Minimising lateral impact derailment potential at level crossings through guard rails." International Journal of Mechanical Sciences 113: 49-60.

Ling, L., Q. Guan, M. Dhanasekar and D. P. Thambiratnam (2016c). "Dynamic simulation of train-truck collision at level crossings." Vehicle System Dynamics: 1-22.

LS-DYNA-Livermore Software Technology Corp. (2015). from http://www.lstc.com/.

Malvar, L. J. and J. E. Crawford (1998). Dynamic increase factors for concrete, Naval Facilities Engineering Service Center Port hueneme CA.

Zhang, Z., M. Dhanasekar, D. P. Thambiratnam and L. Ling (2018). "Dynamics of Tire Crossing on a Gapped Road Surface." Journal of Engineering Mechanics 144(4): 04018013. 